\title{
EFFECT OF USING TWO MUSIC TYPES ON NON-PREGNANT NON-LACTATING ARABI EWES BEHAVIOUR AS A TOOL FOR WELFARE IMPROVEMENT
}

\author{
Ronak A. Meshabaz ${ }^{\text {a*}}$, Nizar J. Hussein a, b, Mhamed A. M. Mersham ${ }^{\text {a }}$ and Mhamed S. S. Mhamed ${ }^{\text {a }}$ \\ ${ }^{\text {a }}$ Dept. Environmental Science, Faculty of Science, University of Zakho, Kurdistan Region - Iraq. \\ (ronak.meshabaz@uoz.edu.krd) \\ ${ }^{\mathrm{b}}$ Dept. Animal Production, College of Agriculture, University of Duhok, Kurdistan Region - Iraq.
}

Received: Jun. 2017 / Accepted: Dec., 2017 / Published: Dec., 2017

https://doi.org/10.25271/2017.5.4.412

\begin{abstract}
:
The present study was designed to determine whether playing two music types will improve behaviour of non-pregnant, nonlactating Arabi sheep. Thirty Arabi ewes, aged $2-3$ years, were included in the study. Ewes were divided into three groups, 10 ewes each. The groups were: Control (with no music exposure); Classic music exposure and Fast music exposure. The sound level for classic and fast music groups was $80 \mathrm{~dB}$ with the frequency of $1 \mathrm{KHz}$. The behavioural data were collected using direct observations for six respective days. Results revealed that using music, both classic and fast, significantly decreased the frequency of aggressive behaviours $(\mathrm{P}<0.001)$, vocalization $(\mathrm{P}<0.01)$, defecation $(\mathrm{P}<0.05)$ and walking behaviour $(\mathrm{P}<0.05)$. In addition, there were significant effects of music on the average time spent standing $(\mathrm{P}<0.01)$, lying and feeding $(\mathrm{P}<0.001)$. Whereas no significant difference was found on the average time spent drinking. It was shown that there were significant differences in time spent lying $(\mathrm{P}<0.01)$ and time spent feeding $(\mathrm{P}<0.01)$ over time. Finally, there was a significant difference in the proportion of time spent lying $(\mathrm{P}<0.001)$ as well as in the proportion of time spent feeding between control and music groups $(\mathrm{P}<0.01)$. From this study, it can be concluded that exposing non-pregnant, non-lactating ewes to classical music is beneficial for ewes' welfare, due to the reduction of aggressive behaviour.
\end{abstract}

KEYWORDS: Music, Arabi sheep, behaviour, welfare.

\section{INTRODUCTION}

Animal welfare, according to Broom (1986), is defined as "as state of individual as regards its attempts to cope with its environment". Difficulties in coping or failing to cope with the environment are both indicators for poor welfare (Broom, 1991). Mental and physical aspects are both included in animal welfare, which allows animals to have all freedoms, including freedom to express normal behaviours (Dolins, 1999; Prunier et al., 2013). Therefore, comprehending the behaviour of an animal is an important aspect in animal welfare. Behavioural expressions allow scientists to determine the animal welfare (Fraser, 2014). Through behavioural observations we can assess whether sheep welfare is impaired through their following actions : increasing vocalzation frequency; less time spent feeding, which is similar to less time spent lying, as well as lesser comfort behaviours and several other parameters, including facial expression (Orgeur et al., 1998; Dwyer et al., 1998; Broekman, 2015). Therefore, to improve animal behaviour, environmental enrichments have been used such as music (O'Brein, 2014). Goats and sheep have a well-developed capacity of hearing (Tracey and Fleming, 2007). Hence, sounds may possibly act as stressors. This depends on their amplitude and frequency (McAdieet al., 1993; Talling et al., 1998; Quaranta et al., 2002; Moore, 2012; Johns et al., 2015). Sheep are able to detect sounds at $-6 \mathrm{~dB}$ and can hear sounds between $125 \mathrm{~Hz}$ to $42 \mathrm{KHz}$, with the best sensitivity at $10 \mathrm{KHz}$ (Heffner and Heffner, 1990).

The effect of music is well documented in humans. It has been widely used as a therapeutic tool in many disorders in humans, for instance, Alzheimer disease (Simmons-Stern et al., 2010; Simmons-Stern et al., 2012), Parkinson disease (de Dreu et al., 2012), depression (Maratos et al., 2008), autistic spectrum disorder (Gold et al., 2006), schizophrenia (Mössler et al., 2011) and aphasia (van der Meulen et al., 2012). Using sensory enrichments, such as music, have been studied in several animals, including sheep, dairy cattle, piglets, goats, mice, rats, fish, horses, monkey and poultry, mainly day-old chicks (Uetake et al., 1997; Campo et al., 2005; de Jonge et al., 2008; $\mathrm{Xu}$ et al., 2009; Papoutsoglou et al., 2010; Stachurska et al., 2015; Xing et al., 2016). Although, using music is a vital tool for improving piglets and dairy cows' welfare and behaviour where it reduces the stress on cows and increases milk yield (O'Brein, 2014). Animals may have negative effects on welfare if they are exposed to the music for long-term like goats in the alpine regions that are permanently equipped with chime bell (Johns et al., 2015). Music does not affect horses' behaviour when they are exposed to short term isolation distress. Moreover, the welfare of young horses improved with relaxing music (Wilson et al., 2011). Anxiety was reduced in mice using classical music (Chikahisa et al., 2006, 2007; Escribano et al., 2014). It was an effective tool in reducing blood pressure in rats (Akiyama and Sutoo, 2011; Nakamura et al., 2007).

Several studies have been undertaken on the effect of sound and noise on lamb and sheep. A study by Sevi et al. (2001) showed that cortisol levels were increased in lambs with increasing the sound levels (Sevi et al., 2001). In addition, the feed intake of sheep was decreased when they were exposed to high sound levels (Harbers et al., 1975), but, the lamb behaviour was not affected with noise at high sound levels (Quaranta et al., 2002). However, little is known about the effect of music on non-pregnant non-lactating sheep behaviour. Therefore, the present study was designed to determine whether playing two music types will improve behaviour of non-pregnant non-lactating Arabi sheep or could worsen it.

\footnotetext{
* Corresponding author

This is an open access under a CC BY-NC-SA 4.0 license (https://creativecommons.org/licenses/by-nc-sa/4.0/)
} 


\section{MATERIALS AND METHODS}

\subsection{The study Site}

This study was carried out in the animal farm of the College of Agriculture, Summel, $15 \mathrm{Km}$ west of Duhok, Kurdistan Region - Iraq, at national grid reference $\left(36^{\circ} 51^{\prime} \mathrm{N}, 52^{\circ} 02^{\prime} \mathrm{E}\right)$ with altitude of $473 \mathrm{~m}$ above the sea level. The study lasted 6 days in November, 2016. Ewes were provided with hay and barley in addition to vitamins and minerals supplementation as well as ewes were given a free access to water.

\subsection{Subjects and treatments}

Thirty Arabi ewes, aged $2-3$ years, were included in this study. Ewes were divided into three groups, 10 ewes each. The groups were: control (with no music exposure), classic music exposure and fast music exposure. The sound level for classic and fast music groups was $80 \mathrm{~dB}$ with the frequency of $1 \mathrm{KHz}$ using stereo wireless Bluetooth speaker (Bluetooth 2.1). The sound volume was tested using a digital sound meter (Voltcraft SL-200, Voltcraft ${ }^{\circledR}$, Germany). Their average weight was $49 \pm$ $5 ; 54 \pm 4$ and $50 \pm 5$, for control, classic and fast music groups, respectively. The study area was $8 * 17 \mathrm{~m}$ (width and length). Animals were placed in their groups 3 days before the study to be adapted with their environment.

\subsection{Data collection}

In the first day of the study, the data were collected only from the control group, followed by a classical music and fast music group in the second and the third day, respectively. Similarly, the procedure was repeated for the other three days for all groups. Each group lasted one-hour observation starting from 11:30 am to $12: 30 \mathrm{pm}$. All behavioural data that were collected in the present study are presented in Table (1) with their descriptions. The behavioural data were collected by 2 observers. The first observer was recording the following behaviours as frequency per unit time: aggressiveness, vocalisation, defecation and walking. Whereas, the other observer recorded lying, standing, feeding and drinking as duration per unit time. The behaviour were observed in 2 mins intervals using instantaneous and scan sampling methods to measure the frequency and the duration of the chosen behaviours. In addition, the following points were considered by observers based on Pifeleti (2011) before recording any behavioural data:

1. Observer must be familiarized with the species interested.

2. The ethogram must be set to contain a list of behaviours that would be catalogued with their descriptions.

3. Animal behaviour scoring must be practised by the observer to obtain accurate behaviours.

Table 1: Ethogram: list of the observed behaviours that were recorded during this study with their descriptions.

\begin{tabular}{cl}
\hline Behaviours & Descriptions \\
\hline Aggressiveness & All agonistic interactions with and without physical contact received in the feeding area with and without \\
Vocalization & Occurrence of each vocal sound was recorded. \\
Defecation & Excretion of faeces in holding pen. \\
Walking & Moving around in pen, not standing stationary. \\
Lying & Lying included resting and sleeping behaviour, when animals were lying on all four legs. \\
Standing & $\begin{array}{l}\text { Standing described the animals standing as well as moving, more precisely, when the feet had to carry the animal's } \\
\text { body weight. } \\
\text { Feeding }\end{array}$ \\
Whinking & Muzzle in contact with water and ingesting water.
\end{tabular}

(Source: adapted from Molony et al., 2002, 2012; Chapagain et al., 2014; Aguilar, 2016)

\subsection{Data analysis}

All the recorded data were stored in the Microsoft Excel spreadsheet, and then, data were prepared for statistical analysis. Thus, all data from each prepared table were projected to Past3 software programme (PAleontological Statistics, Version 3.08) to be analysed (Folk.uio.no., 2016). In addition, summary statistics was obtained from Past3 software programme. Residual plots confirmed by a Shapiro-Wilk normality test showed that all behavioural data to be nonparametric. Therefore, they were analysed using KruskalWallis test followed by a two-sample nonparametric test by using Mann-Whitney U-test to obtain differences between all behavioural observations from both treatments with control.
All tables and graphs were prepared in in the Microsoft Excel spreadsheet.

\section{RESULTS}

Table 2 shows the effect of two music types, classic vs fast, on the behaviour of Arabi sheep in comparison with control. There was a significant effect of music on aggressiveness $(P<$ $0.001)$, vocalization $(P<0.01)$, defecation and walking $(P<$ 0.05 ) behaviours. In addition, there were significant effects of music on the average time spent standing $(P<0.01)$, lying and feeding $(P<0.001)$. Whereas no significant difference was found on the average time spent drinking (Table 3 ). 
Table 2. The effect of music on the behaviour of non-pregnant non-lactating Arabi sheep. The behaviours presented as frequency (mean \pm SE)

\begin{tabular}{|c|c|c|c|c|}
\hline \multirow[t]{2}{*}{ Behaviours } & \multicolumn{3}{|c|}{ Groups } & \multirow{2}{*}{$P$-value } \\
\hline & Control & Classic & Fast & \\
\hline Aggressiveness & $2.12 \pm 0.39^{\mathrm{a}}$ & $2.10 \pm 0.28^{b}$ & $0.27 \pm 0.09^{c}$ & 0.001 \\
\hline Vocalisation & $1.32 \pm 0.36^{\mathrm{a}}$ & $0.02 \pm 0.01^{\mathrm{b}}$ & $0.67 \pm 0.28^{a}$ & 0.01 \\
\hline Defecation & $0.28 \pm 0.07^{\mathrm{a}}$ & $0.13 \pm 0.05^{\mathrm{ab}}$ & $0.12 \pm 0.05^{b}$ & 0.05 \\
\hline Walking & $4.52 \pm 0.61^{\mathrm{ab}}$ & $3.08 \pm 0.43^{\mathrm{a}}$ & $4.63 \pm 0.49^{b}$ & 0.05 \\
\hline
\end{tabular}

Note: Different letters in rows $(\mathrm{a}, \mathrm{b}, \mathrm{c})$ indicates significant differences $(P<0.01)$

Table 3. The effect of music on the behaviour of non-pregnant non-lactating Arabi sheep. The behaviours presented as duration (mean \pm SE) per minute per animal.

\begin{tabular}{ccccc}
\hline \multirow{2}{*}{ Behaviours } & \multicolumn{3}{c}{ Groups } & \multicolumn{2}{c}{ Fast } & \\
\cline { 2 - 5 } & Control & Classic & $0.39 \pm 0.09^{\mathrm{b}}$ & 0.001 \\
Lying & $0.80 \pm 0.07^{\mathrm{a}}$ & $0.22 \pm 0.07^{\mathrm{b}}$ & $1.53 \pm 0.44^{\mathrm{c}}$ & 0.01 \\
Standing & $0.35 \pm 0.07^{\mathrm{a}}$ & $0.68 \pm 0.09^{\mathrm{b}}$ & $0.25 \pm 0.06^{\mathrm{c}}$ & 0.001 \\
Feeding & $0.63 \pm 0.07^{\mathrm{a}}$ & $0.10 \pm 0.01^{\mathrm{b}}$ & $0.008 \pm 0.007^{\mathrm{a}}$ & n.s \\
Drinking & $0.003 \pm 0.002^{\mathrm{a}}$ & $0.006 \pm 0.004^{\mathrm{a}}$ & &
\end{tabular}

Note: Different letters in rows (a,b,c) indicates significant differences N.S means not significant

It is shown in Figure (1) that there were significant differences in time spent lying $(P<0.01)$ and time spent feeding $(P<0.01)$ over time. The control group had spent more time in lying followed by fast and classic music groups. In the first 40 mins of observation, the time spent lying for the fast music group was higher than the classic music group while it was lower in the last 20 mins of observation than fast music group (Figure $1, a)$. Whereas, time spent feeding in the classic music group of sheep was higher than other groups. The control group spent more their time with feeding in the first and last 20 mins than the fast music group (Figure 1,b).

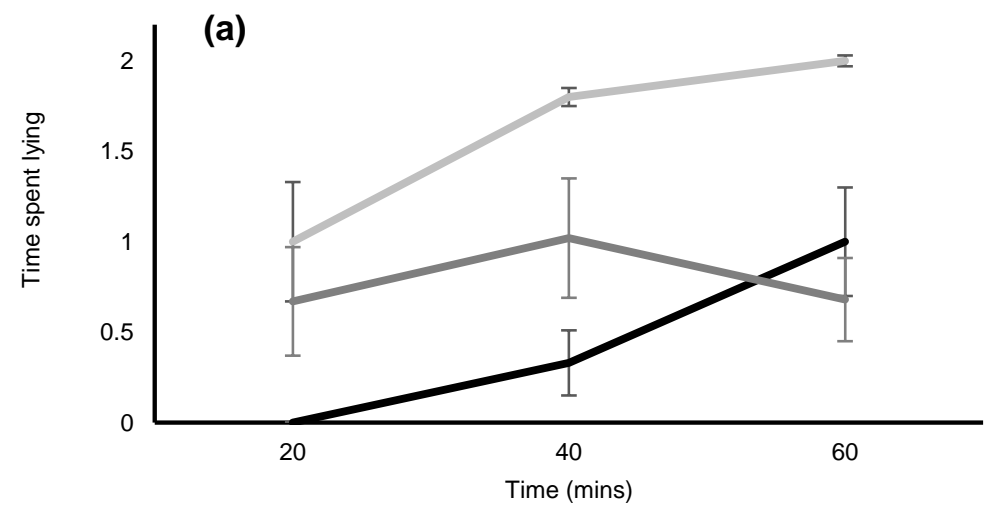

$P<0.001$
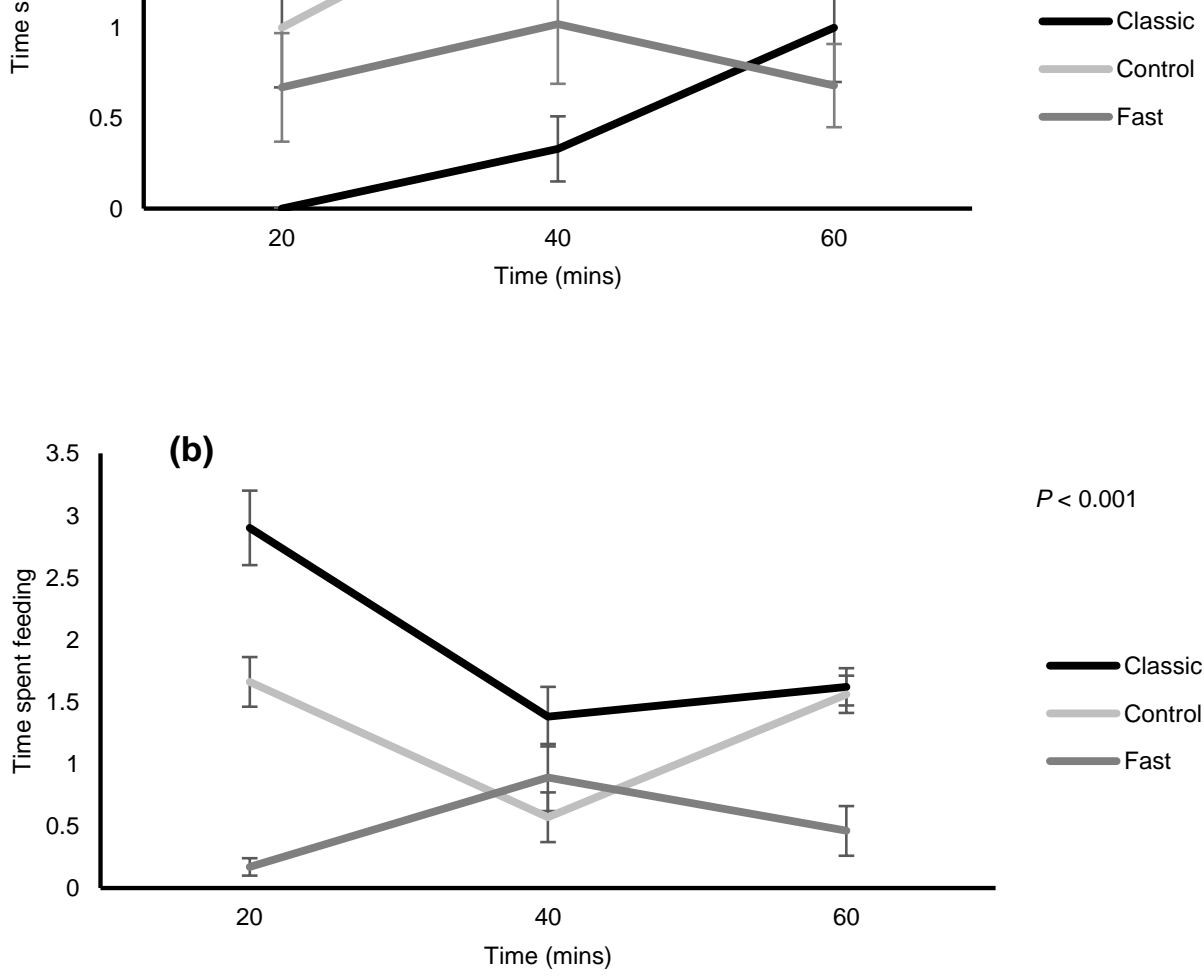

$P<0.001$

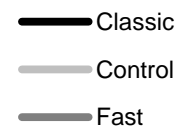

Figure 1. The effect of music on time spent a: lying and b: feeding behaviour of non-pregnant non-lactating Arabi sheep throughout one hour observation. 
The proportions of time spent lying and feeding behaviours are shown in Figure (2). There was a significant difference in the proportion of time spent lying $(P<0.001)$ as well as in the proportion of time spent feeding between control and music groups $(P<0.01)$. The

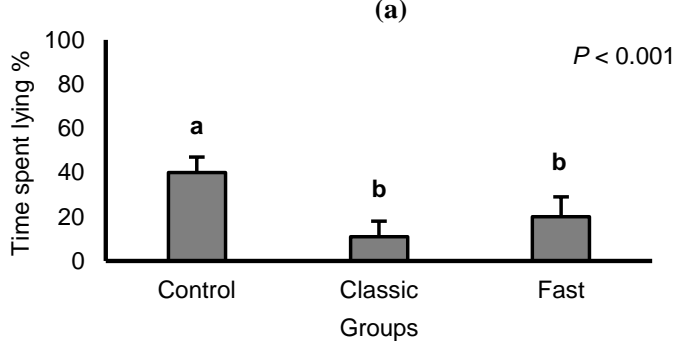

and classic music groups spent $(40 \pm 7),(20 \pm 9)$ and $(11 \pm 7)$ $\%$ of their time with lying behaviour (Figure $2, a)$ and $(32 \pm 7)$, $(13 \pm 6)$ and $(49 \pm 1) \%$ of their time with feeding behaviour, respectively (Figure 2,b).

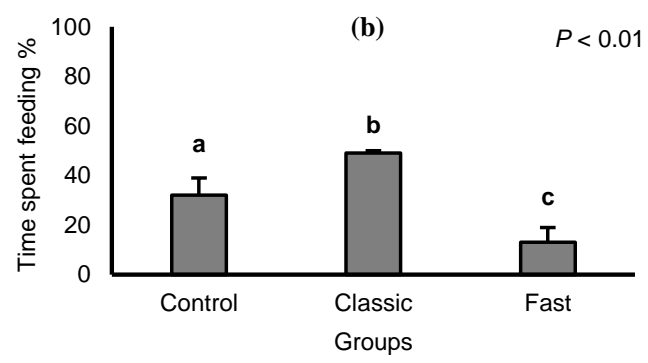

Figure 2. The effect of two music types, classic and fast, on the proportion of a: lying and b: feeding behaviour of non-pregnant non-lactating Arabi sheep.

\section{DISCUSSION}

The main purpose of the present study was elucidating the effect of playing two music types on the behaviour of nonpregnant, non-lactating Arabi sheep. There was a considerable effect of music on the behaviour of sheep. In general, the average time spent feeding and lying per minute was higher in control group $(\mathrm{P}<0.001)$ than the music groups (Table 3$)$. The control group also shows higher aggressiveness $(\mathrm{P}<0.001)$, vocalization $(\mathrm{P}<0.01)$ and defecation $(\mathrm{P}<0.05)$ frequencies per minute than other groups (Table 2 ). In addition, the control group spent $20 \%$ and $29 \%$ more time with lying behaviour (P $<0.001)$ than fast and classic music groups, respectively (Figure 2,a). Whereas, the classic music group spent $12 \%$ and $36 \%$ more time with feeding behaviour $(\mathrm{P}<0.001)$ than control and fast music groups, respectively (Figure 2,b). In the control and classic music groups, time spent lying was increased with time while it was decreasing at the last 20 mins of observation for the fast music group (Figure 1,a); whereas, the classic music group spent more time feeding over time followed by the control and fast music group (Figure 1,b).

Exposing non-pregnant non-lactating Arabi ewes to the music, with sound levels of $80 \mathrm{~dB}$, in the present study reduced aggressive behaviours and vocalization frequency. This indicates that the music does not impair sheep welfare (Broekman, 2015). However, high sound levels, such as $95 \mathrm{~dB}$, did not affect lambs' behaviour (Quaranta et al., 2002). It was found that increasing the noise level from 45 to $95 \mathrm{~dB}$ will increase cortisol hormone levels in the blood, which leads to stress in sheep (Sevi et al., 2001). Whereas, contradictory results were found with using music at $80 \mathrm{~dB}$ in the present study. Similar results were found by Wilson et al. (2011), who found that using music reduced stress in horses. Similarly, music reduced stress, fear and aggression in race horses (Stachurska et al., 2015). Playing music in playroom preweaning reduced aggressiveness in piglets post-weaning (de Jonge et al., 2008). Furthermore, similar to the present study's results on sheep, classical music reduced stress response in chicks at the first week of age (Hafizah et al., 2015). The findings of the present study confirmed that music had a significant effect on sheep behaviour in reducing aggressiveness, even though no significant effect was found of the effect of music on the time spent drinking. Hence, this study's finding was consistent with the previous study's result found by Quaranta et al. (2002).

Classic music ewes spent more time eating than control and fast music groups. This finding is consistent with the previous results found with horses by Wilson et al. (2011), who stated that horses are more likely to eat more than control croup. Although, the sound levels between 75 and $95 \mathrm{~dB}$ decreased feeding time in sheep $(15-19.2 \%)$, compared to control $(24.1 \%)$, the difference was not significant (Quaranta et al., 2002). In the same way, the feed intake of sheep was decreased when they were exposed to the sound levels between $75 \mathrm{~dB}$ and $100 \mathrm{~dB}$ (Harbers et al., 1975). In addition, the feed intake of broilers was not affected with classical music for first five weeks (Hafizah et al., 2015). Therefore, this study's results did not agree with their findings with using classic music, but similar results were found with using fast music in this study, where the percentages of time spent feeding in this study for control, classic and fast music groups were 32, 49 and 13\%, respectively. Thus, this study showed that sheep are likely to eat more feed and spend more time eating when they were exposed to classical music. Exposure of Arabi ewes to $80 \mathrm{~dB}$ decreased lying behaviour significantly comparing to control group (Figure 2,a). Lying behaviour of ewes exposed to $85 \mathrm{~dB}$ was decreased from $38.6 \%$ (control) to $27.2 \%$. However, the difference was not significant (Quaranta et al., 2002). As a result, the present study's finding of lying behaviour was in line with previous research. However, no obvious effect of relaxing music was shown on horses (Wilson et al., 2011).

\section{CONCLUSION}

From the present study, it can be concluded that using music had considerably decreased aggressive behaviours in nonpregnant, non-lactating Arabi ewes. In addition, vocalization frequency was reduced with playing music. Furthermore, classic music, rather than fast music, increased time spent feeding. Therefore, playing music, particularly classic music, is beneficial for sheep welfare, however, concrete conclusion cannot be made as fast music reduced feeding time and both played music types decreased lying time, compared to control group. For that reason, further research is required to elucidate the effect of music on sheep welfare using facial expression, ear postures and behaviour.

\section{REFERENCES}

Aguilar, L. A. (2016). The effect of shearing sheep on feeding and behaviour in the pre-embarkation feedlot (Doctoral dissertation, Murdoch University).

Akiyama, K., and Sutoo, D. E. (2011). Effect of different frequencies of music on blood pressure regulation in spontaneously hypertensive rats. Neuroscience letters, 487(1), 58-60.

Broekman, J. (2015). Welfare impairment of lambs around weaning. Play and other behaviour indicative of affective state. MSc Dissertation, Skara, Sweden. 
Broom, D. M. (1986). Indicators of poor welfare. British veterinary journal, 142(6), 524-526.

Broom, D. M. (1991). Animal welfare: concepts and measurement. Journal of animal science, 69(10), 4167-4175.

Campo, J. L.; Gil, M. G., and Davila, S. G. (2005). Effects of specific noise and music stimuli on stress and fear levels of laying hens of several breeds. Applied Animal Behaviour Science, 91(1), 75-84.

Chapagain, D.; Uvnäs-Moberg, K., and Lidfors, L. M. (2014). Investigating the motivation to play in lambs. Applied Animal Behaviour Science, 160, 6474.

Chikahisa, S.; Sano, A.; Kitaoka, K.; Miyamoto, K. I., and Sei, H. (2007). Anxiolytic effect of music depends on ovarian steroid in female mice. Behavioural brain research, 179(1), 50-59.

Chikahisa, S.; Sei, H.; Morishima, M.; Sano, A. Kitaoka, K.; Nakaya, Y., and Morita, Y. (2006). Exposure to music in the perinatal period enhances learning performance and alters $\mathrm{BDNF} / \mathrm{TrkB}$ signaling in mice as adults. Behavioural brain research, 169(2), 312-319.

De Dreu, M. J.; Van Der Wilk, A. S. D.; Poppe, E., Kwakkel, G., and Van Wegen, E. E. H. (2012). Rehabilitation, exercise therapy and music in patients with Parkinson's disease: a meta-analysis of the effects of music-based movement therapy on walking ability, balance and quality of life. Parkinsonism \& related disorders, 18, S114-S119.

de Jonge, F. H.; Boleij, H.; Baars, A. M.; Dudink, S., and Spruijt, B. M. (2008). Music during play-time: using context conditioning as a tool to improve welfare in piglets. Applied animal behaviour science, 115(3), 138-148.

Dolins, F. L. (1999). Attitudes to animals: Views in animal welfare. Cambridge University Press.

Dwyer, C. M.; McLean, K. A.; Deans, L. A.; Chirnside, J.; Calvert, S. K., and Lawrence, A. B. (1998). Vocalisations between mother and young in sheep: effects of breed and maternal experience. Applied Animal Behaviour Science, 58(1), 105-119.

Escribano, B.; Quero, I.; Feijóo, M.; Tasset, I.; Montilla, P., and Túnez, I. (2014). Role of noise and music as anxiety modulators: Relationship with ovarian hormones in the rat. Applied Animal Behaviour Science, 152, 73-82.

Folk.uio.no. (2016). Past 3.x - the Past of the Future. [Online] Available at: http//: fork.uio.no/ohammer/past/ [Accessed 9 Mar. 2016].

Fraser, D. (2014). The globalisation of farm animal welfare, Revue Scientifique et Technique (International Office of Epizootics), 33 (1), 33-38.

Gold, C., Wigram, T., and Elefant, C. (2006). Music therapy for autistic spectrum disorder. The Cochrane Library.

Hafizah, T., Zulkifli, I. and Soleimani, A.F. (2015). The effect of auditory enrichment on growth performance and stress reaction in broiler chickens. Proceeding of WVPA (Malaysia Branch) and WPSA (Malaysia Branch) Scientific Conference 2015.

Harbers, L. H.; Ames, D. R.; Davis, A. B., and Ahmed, M. B. (1975). Digestive responses of sheep to auditory stimuli. Journal of animal science, 41(2), 654-658.

Heffner, R. S., and Heffner, H. E. (1990). Hearing in domestic pigs (Sus scrofa) and goats (Capra hircus). Hearing research, 48(3), 231-240.

Johns, J., Patt, A., and Hillmann, E. (2015). Effects of sounds of different quality on the behaviour and heart beat parameters of goats. Applied Animal Behaviour Science, 165, 72-80.

Maratos, A.; Gold, C., Wang, X., and Crawford, M. (2008). Music therapy for depression. The Cochrane Library.

McAdie, T. M.; Foster, T. M.; Temple, W., and Matthews, L. R. (1993). A method for measuring the aversiveness of sounds to domestic hens. Applied Animal Behaviour Science, 37(3), 223-238.

Molony, V.; Kent, J. E., and McKendrick, I. J. (2002). Validation of a method for assessment of an acute pain in lambs. Applied animal behaviour science, 76(3), 215-238.

Molony, V.; Kent, J. E.; Viñuela-Fernández, I.; Anderson, C., and Dwyer, C. M. (2012). Pain in lambs castrated at 2days using novel smaller and tighter rubber rings without and with local anaesthetic. The Veterinary Journal, 193(1), 81-86.

Moore, B. C. (2012). An introduction to the psychology of hearing. Brill.

Mössler, K.; Chen, X.; Heldal, T. O., and Gold, C. (2011). Music therapy for people with schizophrenia and schizophrenia-like disorders. The Cochrane Library.

Nakamura, T.; Tanida, M.; Niijima, A.; Hibino, H.; Shen, J., and Nagai, K. (2007). Auditory stimulation affects renal sympathetic nerve activity and blood pressure in rats. Neuroscience letters, 416(2), 107-112.

O'Brein, A. (2014) Milking to Music. Retrieved from: http://modernfarmer.com/2014/02/milking-music/

Orgeur, P.; Mavric, N.; Yvore, P.; Bernard, S.; Nowak, R.; Schaal, B., and Levy, F. (1998). Artificial weaning in sheep: consequences on behavioural, hormonal and immuno-pathological indicators of welfare. Applied Animal Behaviour Science, 58(1), 87-103.

Papoutsoglou, S. E.; Karakatsouli, N.; Papoutsoglou, E. S., and Vasilikos, G. (2010). Common carp (Cyprinus carpio) response to two pieces of music ("Eine Kleine Nachtmusik" and "Romanza") combined with light intensity, using recirculating water system. Fish physiology and biochemistry, 36(3), 539-554.

Pifeliti, S. (2011). The effect of early painful experiences on subsequent pain sensitivity in lambs: a thesis submitted in partial fulfilment of the requirements for the degree of Master of Science in Physiology at Massey University, Manawatu, New Zealand.

Prunier, A.; Mounier, L.; Le Neindre, P.; Leterrier, C.; Mormède, P.; Paulmier, V.; Prunet, P.; Terlouw, C. and Guatteo, R. (2013). Identifying and monitoring pain in farm animals: a review. Animal, 7(06), 9981010 .

Quaranta, A., Sevi, A., Nardomarino, A., Colella, G. E., and Casamassima, D. (2002). Effects of graded noise levels on behavior, physiology and production performance of intensively managed lambs. Italian Journal of Animal Science, 1, 217-227.

Sevi, A., Quaranta, A., Nardomarino, A., Bellitti, A., Colella, G. E.,and Casamassima, D. (2001). Effetti del rumore su alcuni parametri fisiologici, produttivie comportamentali dell'agnello allevato intensivamente. Nutrient. Animal. 27, 3-13.

Simmons-Stern, N. R.; Budson, A. E., and Ally, B. A. (2010). Music as a memory enhancer in patients with Alzheimer's disease. Neuropsychologia, 48 (10), 3164-3167.

Simmons-Stern, N. R.; Deason, R. G.; Brandler, B. J.; Frustace, B. S.; O'Connor, M. K.; Ally, B. A., and Budson, A. E. (2012). Music-based memory 
enhancement in Alzheimer's disease: Promise and limitations. Neuropsychologia, 50 (14), 3295-3303.

Stachurska, A.; Janczarek, I.; Wilk, I., and Kędzierski, W. (2015). Does music influence emotional state in race horses?. Journal of Equine Veterinary Science, 35(8), 650-656.

Talling, J. C.; Waran, N. K.; Wathes, C. M., and Lines, J. A. (1998). Sound avoidance by domestic pigs depends upon characteristics of the signal. Applied Animal Behaviour Science, 58(3), 255-266.

Tracey, J. P., and Fleming, P. J. (2007). Behavioural responses of feral goats (Capra hircus) to helicopters. Applied Animal Behaviour Science, 108(1), 114-128.

Uetake, K.; Hurnik, J. F., and Johnson, L. (1997). Effect of music on voluntary approach of dairy cows to an automatic milking system. Applied animal behaviour science, 53(3), 175-182.

van der Meulen, I.; van de Sandt-Koenderman, M. E., and Ribbers, G. M. (2012). Melodic intonation therapy: present controversies and future opportunities. Archives of physical medicine and rehabilitation, 93(1), S46-S52.

Wilson, M. E., Phillips, C. J. C.; Lisle, A. T.; Anderson, S. T.; Bryden, W. L., and Cawdell-Smith, A. J. (2011). Effect of music on the behavioural and physiological responses of stabled weanlings. Journal of Equine Veterinary Science, 31(5), 321-322.

Xing, Y., Chen, W., Wang, Y., Jing, W., Gao, S., Guo, D.; Xia, Y., and Yao, D. (2016). Music exposure improves spatial cognition by enhancing the BDNF level of dorsal hippocampal subregions in the developing rats. Brain research bulletin, 121, 131-137.

Xu, J.; Yu, L.; Cai, R.; Zhang, J., and Sun, X. (2009). Early auditory enrichment with music enhances auditory discrimination learning and alters NR2B protein expression in rat auditory cortex. Behavioural brain research, 196(1), 49-54. 